\title{
Infracciones, penas y multas por maltrato animal en América Latina
}

\author{
Infractions, penalties and fines for animal abuse in Latin America \\ Sebastián Andrés Ortega Peñafiel ' (D), María Diana Maldonado Cabrera² (D) Leiner \\ Geanella Bejarano Paz ${ }^{3}$ iD , Victoria Elizabeth Freire Goyes ${ }^{4}$
}

\section{Cómo citar}

Ortega Peñafiel, S. A., Maldonado Cabrera, M. D., Bejarano Paz, L. G. y Freire Goyes, V. E. (2021). Infracciones, penas y multas por maltrato animal en América Latina. Socialium, 5(1), 226-241. https://doi.org/10.26490/uncp.sl.2021.5.1.815

\footnotetext{
${ }^{1}$ Magister en Derecho Procesal, Abogado,

Universidad Católica de Cuenca, Cuenca, Ecuador.

sebastian.ortega@ucacue.edu.ec Google Scholar

${ }^{2}$ Magister en Derecho Civil, Abogada, Universidad Católica de Cuenca, Cuenca Ecuador. maria.maldonado@ucacue.edu.ec Google Scholar

${ }^{3}$ Estudiante, Universidad Católica de Cuenca, Cuenca Ecuador.

leinerbejarano@hotmail.com Google Scholar

${ }^{4}$ Estudiante, Universidad Católica de Cuenca, Cuenca Ecuador. vefg702@gmail.com Google Scholar
}

Arbitrado por pares ciegos Recibido: $12 / 08 / 2020$ Aceptado: 22/12/20

\section{RESUMEN}

La sociedad sufre distintos tipos de violencia, entre los cuales se encuentra el maltrato de animales domésticos, el objetivo de la investigación fue analizar la infracciones, penas y multas por maltrato animal en América Latina. El método utilizado fue es la revisión bibliográfica en publicaciones recientes y documental con las distintas normas jurídicas propias de cada país referentes a la temática, el diseño fue descriptivo - argumentativo, la recolección de la información parte con la utilización de base de datos, Radalyc, Proquest y Scopus. Como resultado se halló que algunos Estados latinoamericanos regulan el maltrato animal como infracciones de materia penal, delitos y contravenciones y otros como infracciones administrativas, leves, graves y muy graves. Se concluyó que en América Latina el maltrato animal es uno de los mayores problemas que enfrenta la sociedad, por lo que se debe proteger a los animales como sujetos de derechos respetando su condición de vulnerabilidad. Para prevenir y erradicar el maltrato animal no solo basta normas sancionadoras, es importante la educación desde el hogar, centros educativos y sociedad.

Palabras clave: maltrato animal; América Latina; infracciones; sanciones; vulnerables.

\section{ABSTRACT}

Society suffers different types of violence, among which is the mistreatment of domestic animals, the objective of the research was to analyze the infractions, penalties and fines for animal mistreatment in Latin America. The method used was the bibliographic review of recent publications and documents with the different legal norms of each country related to the subject, the design was descriptive-argumentative, the collection of information started with the use of databases, Radalyc, Proquest and Scopus. As a result, it was found that some Latin American States regulate animal abuse as criminal offenses, crimes and contraventions and others as administrative, minor, serious and very serious offenses. It was concluded that in Latin America, animal abuse is one of the greatest problems facing society, so animals must be protected as subjects of rights while respecting their vulnerable condition. In order to prevent and eradicate animal abuse, it is not only enough to have punitive norms, it is also important to educate from home, educational centers and society.

Keywords: animal abuse; Latin America; infractions; sanctions; vulnerable. 


\section{Introducción}

El presente trabajo investigativo sobre el maltrato de animales domésticos nace de la necesidad de proporcionar asesoría jurídica gratuita en todas las áreas del derecho de manera eficiente, eficaz y de calidad para la defensa de la igualdad, la libertad, la verdad y la justicia, como objetivo específico dentro del Proyecto de Vinculación denominado Asesoramiento y Patrocinio Jurídico Gratuito ejecutado por la Universidad Católica de Cuenca, carrera de Derecho, extensión de La Troncal.

En el desarrollo de la presente investigación, se analiza las infracciones, penas y multas en América Latina por maltrato animal, violencia que con el trascurrir del tiempo ha sido ejercido de forma arbitraria a pesar de estar considerado como un delito en varios países, cada día va en aumento el comportamiento violento, cruel y el abandono hacia los animales, esta clase de irrespeto debe prevenirse y erradicarse de forma definitiva, siendo corresponsabilidad del Estado y la sociedad, defender los derechos de aquellos seres vivos no humanos, pero que sienten dolor y sufrimiento al ser víctimas de violencia sin posibilidad alguna de defenderse.

La violencia contra los animales domésticos desde el punto de partida del Derecho natural exceptúa a los animales como sujetos de Derecho, esta ideología se ha transformado a una concepción más iuspositivista que admite que seres diferentes de los humanos puedan ser objeto de protección por ser titulares de derechos (García, 2015).

Mientras que la doctrina considera que el maltrato de animales domésticos no es un delito contra el medio ambiente, en consideración que, al tratarse precisamente de domésticos, las conductas de maltrato, abandono y demás ejercidos contra estos tienen efectos económicos, morales o de cualquier otra índole, pero no tienen ningún tipo de trascendencia en el equilibrio ambiental, como sí ocurre con los delitos contra la flora y fauna (Jaurrieta, 2019).

Por su parte, la denominada Ley Cholito (Honorable Congreso Nacional, 2017) define a las mascotas o animales de compañía: como aquellos animales domésticos, de cualquier especie, para fines de compañía o seguridad. Por su parte, la ley de protección y promoción del bienestar de animales de compañía (Asamblea Legislativa, 2016) considera como animales de compañía o mascotas a los perros, gatos u otros animales domésticos para dar compañía a su propietario, poseedor o tenedor.

Encontramos distintos factores importantes para el maltrato de animales domésticos, como son: la ausencia de educación dirigida al bienestar de los animales debe plantearse con la idea de generar en la sociedad que no se debe maltratar a los animales (Mazas y Fernández, 2016). La impunidad, falta de procesos de transformación social, la ausencia de investigaciones o de prosecución de casos, 
generando incertidumbre y desconfianza para los ciudadanos denunciantes de las infracciones para la protección de los animales (Estrada y Pinto, 2018).

En general a los animales se les consideran carentes de dignidad humana, en esta línea explicativa son entendidos como cosas, pero sujetos de protección jurídica (Virgen, 2016). Debemos partir de la abolición de la propiedad sobre los animales para garantizar el reconocimiento del estatus normativo como sujetos de derecho (Mañalich,2018).

Diversos movimientos que fomentan el cuidado animal como la correcta educación del hombre y toda la sociedad, promoviendo reflexiones críticas sobre el maltrato animal (Pérez, 2019). Existe una relación afectiva auténtica y multidimensional con los animales de compañía que es el afecto, tanto de los humanos dirigida a los animales como de los animales a los humanos (Acero, 2019).

Por otra parte, la corriente extremista sería la eliminación de la característica de apropiabilidad sobre los animales y, por esta razón, dotarlos de autonomía de derechos en relación a los humanos, sin embargo, esto conllevaría afectaciones industriales, en los negocios jurídicos incluso en las prácticas culturales (Molano y Murcia, 2018).

Es necesario mencionar lo que ocurre en el hinduismo, cuya religión establece a las vacas como seres sagrados revestidos de espiritualidad y con representación de dioses en la tierra, estos animales son considerados como hermanos y miembros de la familia. Por su parte el jainismo, establece como prácticas de convivencia la no violencia (ahisma) el cual incluye el caminar descalzo y con cuidado, para no matar a los insectos que estén en el piso (Marín, 2001).

Los animales eran, son y serán parte de nuestras vidas; aún más cuando hablamos de los que hemos acogido en el hogar, suponiendo será para la protección y cuidado del mismo, sin embargo, no siempre es el caso y allí surge la necesidad de incorporar una ley que proteja a los miembros de este grupo vulnerable. La relación de los animales con el ser humano ha sido objeto de un profundo análisis, inicialmente los animales eran exceptuados como sujetos de derecho según la perspectiva del Derecho Natural, sin embargo, esta concepción ha evolucionado admitiendo que no solo los seres humanos somos sujetos de derecho. Actualmente existen diversas organizaciones que fomentan el cuidado y protección animal a través de la concientización y adoctrinamiento del hombre y la sociedad.

El objetivo de la investigación fue analizar del maltrato animal en América Latina, dando a conocer las infracciones, penas, y multas para determinar su protección jurídica para evitar su impunidad. Con los grandes avances que hemos logrado como sociedad en varios aspectos aún vivimos en una 
cultura de violencia e irrespeto por la vida en todas sus formas, en especial en la de aquellos que no se pueden defender.

\section{Método}

Como método se aplicó el estudio bibliográfico de la normativa latinoamericana correspondiente al maltrato de los animales domésticos de los siguientes países: Argentina, Bolivia, Brasil, Chile, Colombia, Costa Rica, Cuba, Ecuador, El Salvador, Guatemala, Honduras, México, Nicaragua, Panamá, Paraguay, Perú, Puerto Rico, República Dominicana, Uruguay y Venezuela.

La recolección de datos se realizó en los principales de artículos indexados de revistas internacionales en las bases de datos: Redalyc, Scopus y Proquest sobre tendencias actuales del maltrato animal de los últimos 5 años.

Finalmente, se utilizó la discusión crítica con el objetivo de establecer criterios sobre la temática a tratar y establecer las infracciones, penal y multas en América Latina establecidas en la Región objeto del análisis, no obstante, a pesar de los distintos esfuerzos realizados por los Estados, se evidencian las debilidades y sobre todo el incremento de la violencia en contra de los animales domésticos.

\section{Análisis de la protección jurídica de las Infracciones, penas y multas por maltrato de animales domésticos en América Latina}

Argentina tiene la Ley 14.346 (Honorable Congreso de la Nación Argentina,1954) regula especialmente las conductas de actos de crueldad contra los animales como: abandonarlos, mutilar cualquier parte del cuerpo, lastimarlos, práctica de riñas entre otros y actos de maltrato como: no alimentarlos, estimularlos con drogas o azuzarlos para el trabajo. Estas conductas se deben denunciar en las comisarías, fiscalía y juzgados de instrucción.

Brasil mediante su Código Penal (Congreso Nacional, 1940) establece diversas infracciones para la protección de animales. El deber de protección animal exige al legislador y al intérprete constitucional establecer criterios de razonabilidad o proporcionalidad que fundamenten las excepciones a la protección animal en los ordenamientos jurídicos (Demanda de Inconstitucionalidad, 2019).

Bolivia cuenta con la Ley 700 (La Asamblea Legislativa Plurinacional, 2015) denominada como la ley para la defensa de los animales domésticos contra actos de crueldad y maltrato cuya finalidad es de 
prevenir y penalizar todo acto de violencia, crueldad, maltrato y biocidio. Esta norma jurídica tiene una gran iniciativa al reconocer derechos propios de los animales como seres vivos, contar con un ambiente saludable y ser auxiliados.

Chile considera como problemática social al maltrato animal y para poder afrontarlo se debe partir desde la educación moral de los adolescentes y personas (Mujica, 2019). Regula la Ley de Tenencia Responsable de Mascotas y Animales de Compañía (Honorable Congreso Nacional, 2017) y establece como uno de sus objetivos la protección de la salud y bienestar animal, instaura estrategias de protección, control de la población animal y centros de mantención temporal. Mientras que el Código Penal (Honorable Congreso Nacional, 2009) establece las infracciones como: la propagación de enfermedad y actos de crueldad y maltrato animal.

En Colombia en los últimos años mediante las movilizaciones de las distintas organizaciones contra el maltrato animal especialmente en Bogotá han despertado mayor grado de conciencia por parte de la sociedad frente a esta problemática (Parra y Pinzón 2015). Este país cuenta con la Ley 1774 (Congreso, 2016) que modificó el Código Civil, Código Penal y Código de Procedimiento Penal para decretar que los animales no son cosas, son seres sintientes que merecen una protección especial por las conductas causadas por los humanos, se aborda el bienestar animal, solidaridad social y se establece un procedimiento sancionador de carácter policial y judicial.

Cuba regula el Código Penal (Asamblea Nacional, 1987) denominada la Ley $N^{\circ} 62$ que regula las conductas contra los animales. Sin embargo, no regula de manera específica a los animales domésticos. Actualmente existe la denominada Zoonosis que cuenta con diversas entidades como el Centro de Observación Canina que tiene como función recoger temporalmente a animales como gatos y perros si no son reclamados en 72 horas proceden con su sacrificio.

Ecuador considera a la naturaleza o pacha mama como sujeto de derechos como así lo establece la Constitución de la República (Asamblea Nacional del Ecuador, 2008). Mientras tanto el Código Orgánico Integral Penal (Asamblea Nacional del Ecuador, 2014) en su capítulo cuarto tipifica las infracciones contra el medio ambiente y la naturaleza, es necesario resaltar la reforma que entró en vigencia el 21 de junio del 2020 la cual implementa nuevos delitos y contravenciones castigados de manera más severa a favor de los animales domésticos e implementa un nuevo procedimiento privado del ejercicio de la acción para sustanciar esta clase de delitos.

El Salvador cuenta con la ley de protección y promoción del bienestar de animales de compañía (Asamblea Legislativa, 2016) cuya finalidad es: generar una cultura social mediante la educación que respete la vida, el buen cuidado, la salud, bienestar de los animales de compañía, la participación en 
la adopción de medidas para la protección, la prevención y erradicación de todo tipo de maltrato y acto de crueldad. Una característica muy importante de esta norma jurídica es la tipificación de infracciones administrativas leves, graves y muy graves.

Guatemala regula la ley de Protección y Bienestar Animal (Congreso de la República, 2017) tiene como iniciativa dotar de reconocimiento jurídico a los animales como seres sintientes, establecer norma de protección, fomentar la conciencia, respecto de todos los seres vivos, prevenir, promover, erradicar, penalizar y sancionar toda clase de conducta que vulnere los derechos de los animales. Finalmente, ese país cuenta con las siguientes entidades: Unidad de Bienestar Animal y la Comisión Nacional para la protección de los animales.

Honduras cuenta con la Ley de Protección y Bienestar Animal (Congreso Nacional, 2015) y define al maltrato animal como las conductas que causan dolor innecesario o generen estrés al animal, estos comportamientos van desde la negligencia o descuido de los cuidados básicos hasta la muerte maliciosa. Cuenta con el Consejo Nacional de Protección y Bienestar Animal con las siguientes funciones: brindar asesoría, promover programas, estrategias de educación, concientización, investigación sobre la protección de los animales.

México con la Ley de Protección a los Animales del Distrito Federal (Asamblea Legislativa del Distrito Federal, 2002) asegura la sanidad animal, buen trato, desarrollo natural, manutención, alojamiento de los animales y prohíbe todo acto de sufrimiento, crueldad y de zoofilia. La Secretaría de Seguridad Pública dentro de sus funciones tiene: rescatar, brindar protección, y responder a situaciones de riesgo a favor de los animales.

Nicaragua regula la Ley para la protección y el bienestar de los animales domésticos y animales silvestres domesticados (Asamblea Nacional, 2011) normativa que protege la integridad física y psicológica, desarrollo natural, vela por las condiciones básicas, cuidado, prevención de enfermedades, nutrición de los animales domésticos. El Ministerio Agropecuario y Forestal conjuntamente con los Gobiernos Municipales son los organismos competentes para aplicar la referida norma jurídica.

Panamá por su parte cuenta con la Ley 70 (Asamblea Nacional, 2012) y garantiza que el animal doméstico que el dueño haya escogido como mascota, tiene derecho conforme su longevidad de su vida a un trato digno, alimentación adecuada, cuidado, reposo, atención, protección y no deberá ser sometido a actos de crueldad ni a malos tratos. Establece medidas zoosanitarias como: mantener libre el acceso a alimentos, agua, recolectar los excrementos, si el animal está amarrado mantener la 
cadena a una distancia prudencial que le permita acceder a su fuente de alimentación, moverse, descansar y llevar al día el registro de vacunas o control veterinario.

Paraguay establece pautas mínimas para la protección de los animales con la Ley N 4840 (Congreso de la Nación, 2013) cuenta con la Dirección Nacional de Defensa, Salud y Bienestar Animal con las siguientes funciones: albergue, rescate, esterilización de los animales, recibir denuncias, promover acciones en vía judicial, solicitar medidas cautelares, allanamientos, secuestro y liberación de animales en estado de emergencia. Otro aspecto a destacar es la capacidad de arrendar, comprar o enajenar bienes muebles e inmuebles en beneficio de los animales domésticos.

Perú tiene la Ley N³04087 (Congreso de la República, 2016) que establece como principio rector que los animales vertebrados domésticos son seres sensibles y tienen derecho a un buen trato y vivir en armonía con las personas. Un aspecto a resaltar es la conformación de Asociaciones sin fines de lucro para la protección y defensa de los animales. Finalmente, regula la eutanacia y sus métodos, la misma procederá con el consentimiento por escrito de su propietario.

República Dominicana cuenta con la Ley No. 248-12 (Congreso Nacional, 2012) vela por el bienestar y salud de los animales, fomenta la conciencia social, previene la crueldad y maltrato animal. El Ministerio de Salud Pública y Asistencia Social tiene como una de sus obligaciones, promover y despertar a la ciudadanía el respeto a la vida y derechos de los animales domésticos.

Uruguay tiene por finalidad la protección de los animales en su vida y bienestar con la Ley № 18.471 (El Senado y la Cámara de Representantes de la República Oriental, 2012) establece condiciones mínimas dentro de las cuales los dueños, propietarios o poseedores deberán mantener a los animales en condiciones sanitarias, físicas y alimenticias adecuadas. La Comisión Nacional Honoraria de Tenencia Responsable y Bienestar Animal es la autoridad competente responsable para la revisión y control del estado de los animales.

Venezuela regula la Ley para la protección de la fauna doméstica libre y en cautiverio (Asamblea Nacional,2010) define el bienestar de la fauna doméstica como el conjunto de acciones para garantizar la integridad física y psicológica, así como, evitar el sufrimiento, maltrato, actos de crueldad y de abandono de los animales. Establece restricciones a la propiedad y tenencia de animales domésticos como el hacinamiento, practicarles mutilaciones, ser objeto de blanco de tiro, realizar el proceso de castración sin la anestesia previa y abandonarlos en vías públicas.

Luego de un profundo análisis a las diversas leyes en países de Latinoamérica se evidencia que no en todos ellos existen leyes específicas para el cuidado y protección animal, sin embargo, se encuentran 
amparados por el Derecho Penal como delitos de ejercicio público y privado y dentro del derecho administrativo están sancionadas como infracciones leves, graves y muy graves.

En base a lo analizado en la normativa latinoamericana respecto de todo entorno al maltrato de los animales domésticos, deducimos que a pesar de que existen normativas establecidas con el fin de reconocer a los animales derechos propios como seres vivos, dejando así de lado la ideología errónea de que los animales no son cosas carentes de sentimientos y sensaciones, reconociendo a estos como seres merecedores de protección.

Existe una valoración mínima hacia la vida de las mascotas, puesto que, las penas impuestas son generalmente leves a comparación de las impuestas por otros actos que no conllevan el quitar una vida, deberíamos recordar que todas las vidas importan y aún más cuando a quien se la están arrebatando es un ser en estado de indefensión.

\section{Resultado del Análisis de la protección jurídica de las Infracciones, penas y multas por maltrato de animales domésticos en América Latinas}

Los resultados se reflejan en la siguiente tabla, en la que se realizó un análisis de cada uno de los países que conforman América Latina, para poder interpretar debemos considerar la protección jurídica hacia los animales domésticos, en algunos Estados, se regulan como infracciones en materia penal, delitos y contravenciones, en otros, surgen como infracciones administrativas, leves, graves y muy graves, finalmente se identificó la penalidad y multas quien vulnere los derechos de los seres vivos.

\section{Tabla 1}

Infracciones, penas y multas por maltrato de animales domésticos en América Latina

\begin{tabular}{lll}
\hline País & Infracción & \multicolumn{1}{c}{ Penas y multas } \\
\hline Argentina & $\begin{array}{l}\text { Malos tratos o hiciere víctima de actos } \\
\text { de crueldad a los animales. } \\
\text { Actos de crueldad }\end{array}$ & $\begin{array}{l}\text { Son reprimidos desde prisión de quince } \\
\text { días hasta un año. }\end{array}$ \\
\hline Brasil & $\begin{array}{l}\text { Suprimir o alterar, indebidamente, en el } \\
\text { ganado o rebaño ajeno, marca o señal } \\
\text { código de propiedad. }\end{array}$ & $\begin{array}{l}\text { Detención, de seis meses a tres años, y } \\
\text { multa. }\end{array}$ \\
& $\begin{array}{l}\text { Introducir o dejar animales en } \\
\text { propiedad ajena, sin el consentimiento de quince días a seis meses, } \\
\text { o multa. }\end{array}$ & Prisión, de dos a cinco años, y multa. \\
\hline
\end{tabular}


de los mismos y que el hecho resulte en una pérdida.

Propagar enfermedades o plagas que puedan causar daño al bosque, plantación o animales que tienen utilidad económica.

\begin{tabular}{lll}
\hline Bolivia & Tratos crueles. & Son sancionados con privación de la \\
Biocidio & libertad de seis meses hasta cinco años. \\
& Multa de treinta a sesenta días o \\
& prestación de servicios de tres a seis \\
& meses.
\end{tabular}

\begin{tabular}{lll}
\hline Chile & $\begin{array}{l}\text { Propagación de una enfermedad } \\
\text { animal. }\end{array}$ & $\begin{array}{l}\text { Tienen una pena privativa de libertad de } \\
\text { Actos de maltrato o crueldad animal. }\end{array}$ \\
& $\begin{array}{l}\text { sesenta a quinientos cuarenta días y } \\
\text { multa de dos a treinta de Unidades } \\
\text { Tributarias Mensuales. }\end{array}$ \\
\hline
\end{tabular}

Colombia Delitos contra la vida, la integridad física y emocional de los animales
Se penaliza con prisión de doce a treinta y seis meses, inhabilitación especial de uno a tres años para el ejercicio de profesión, comercio, oficio o tenencia que tenga relación con los animales y multa de cinco a sesenta salarios mínimos mensuales legales vigentes.

Privación de libertad de dos a diez años. Privación de libertad de tres meses a un año o multa de cien a trescientas cuotas o ambas.
Obstaculización de centros de investigación, cría o desarrollo de especies animales.

No informar a las autoridades sanitarias de los casos de animales que presenten síntomas o padezcan enfermedades susceptibles de ser transmitidas a otros animales. Infringir las disposiciones orientadas a prevenir, combatir o destruir las enfermedades y plagas de animales y vegetales.
Ecuador
Delitos: Lesiones a animales que formen parte del ámbito de la fauna urbana.

Abuso sexual a animales que forman parte del ámbito de la fauna urbana. Muerte a animal que forma parte del ámbito de la fauna urbana.

Peleas o combates entre perros u otros animales de fauna urbana
En los delitos las penas privativas de libertad van desde dos días hasta tres años y las multas son desde uno hasta diez salarios básicos unificados.

En las contravenciones se sancionan con trabajo comunitario desde veinte hasta cien horas sin multa. 
Contravenciones: Abandono de animales de compañía.

Maltrato a animales que forman parte del ámbito de la fauna urbana.

\begin{tabular}{|c|c|c|}
\hline El Salvador & $\begin{array}{l}\text { Infracciones administrativas: } \\
\text { Leve. } \\
\text { Grave. } \\
\text { Muy Grave. }\end{array}$ & $\begin{array}{l}\text { Las infracciones leves son sancionadas } \\
\text { con multa hasta un salario mínimo del } \\
\text { sector comercio y servicio } \\
\text { Las infracciones graves son sancionadas } \\
\text { con multa comprendida de uno hasta } \\
\text { tres salarios mínimos del sector } \\
\text { comercio y servicio } \\
\text { Las infracciones muy graves son } \\
\text { sancionadas con multa comprendida de } \\
\text { tres hasta cuatro salarios mínimos del } \\
\text { sector comercio y servicio. }\end{array}$ \\
\hline Guatemala & $\begin{array}{l}\text { Se clasifican en: } \\
\text { Graves. } \\
\text { Muy graves. } \\
\text { Gravísimas } \\
\text { Negligencia criminal. }\end{array}$ & $\begin{array}{l}\text { Las infracciones graves serán } \\
\text { sancionadas con multa equivalente a } \\
\text { cuatro salarios mínimos mensuales. } \\
\text { Las infracciones muy graves serán } \\
\text { sancionadas con multa equivalente a } \\
\text { ocho salarios mínimos mensuales. } \\
\text { Las Infracciones gravísimas serán } \\
\text { sancionadas con multa de doce salarios } \\
\text { mínimos mensuales. } \\
\text { Negligencia criminal sancionada desde } \\
\text { doce salarios mínimos mensuales. }\end{array}$ \\
\hline Honduras & $\begin{array}{l}\text { Se clasifican en infracciones: } \\
\text { Leves. } \\
\text { Graves. } \\
\text { Muy graves. } \\
\text { Delito de maltrato animal. }\end{array}$ & $\begin{array}{l}\text { Las infracciones leves son sancionadas } \\
\text { de uno a cinco salarios mínimos. } \\
\text { Las infracciones graves de cinco salarios } \\
\text { mínimos un día a diez salarios mínimos. } \\
\text { Las infracciones muy graves, de diez } \\
\text { salarios mínimos un día a veinticinco } \\
\text { salarios mínimos. } \\
\text { El delito de maltrato animal es } \\
\text { sancionado de tres a cinco años y multa } \\
\text { de diez hasta veinte y cinco salarios } \\
\text { mínimos. }\end{array}$ \\
\hline México & $\begin{array}{l}\text { Actos de crueldad o maltrato } \\
\text { Actos de daño o tortura }\end{array}$ & $\begin{array}{l}\text { Amonestación; } \\
\text { Multa } \\
\text { Arresto; } \\
\text { Las demás que señalen las leyes o } \\
\text { reglamentos. } \\
\text { Son sancionadas con multa de veintiuno } \\
\text { hasta treinta veces la Unidad de Cuenta } \\
\text { vigente y con arresto de veinte y cuatro } \\
\text { a treinta y seis horas. }\end{array}$ \\
\hline
\end{tabular}


Nicaragua
Las sanciones administrativas podrán ser:

Amonestación;

Multas desde cien a tres mil días.

Decomiso en las infracciones graves y muy graves;

Cierre temporal 0 definitivo de establecimientos.

Prohibición temporal o definitiva del ejercicio de comercio de animales.

Prohibición de tenencia de animales.

Trabajo comunitario.

\begin{tabular}{|c|c|c|}
\hline Panamá & $\begin{array}{l}\text { Lesiones o muerte a un animal } \\
\text { mediante actos de crueldad. } \\
\text { Zoofilia. } \\
\text { Privación de alimentos. } \\
\text { Condiciones higiénicas inadecuadas, no } \\
\text { proveer tratamiento médico } \\
\text { veterinario, no protegerlo contra las } \\
\text { inclemencias del tiempo. } \\
\text { Mantener en jaulas inadecuadas según } \\
\text { su especie y tamaño. } \\
\text { Contravenir el propietario o } \\
\text { responsable del animal doméstico las } \\
\text { disposiciones establecidas. }\end{array}$ & $\begin{array}{l}\text { Las sanciones se establecerán con } \\
\text { multas de quinientos balboas a mil } \\
\text { balboas y con trabajo comunitario. } \\
\text { Las sanciones serán multa de cien } \\
\text { balboas a quinientos balboas y con } \\
\text { trabajo comunitario. }\end{array}$ \\
\hline Paraguay & $\begin{array}{l}\text { Las infracciones se califican en: } \\
\text { Leves. } \\
\text { Graves. } \\
\text { Muy graves. }\end{array}$ & $\begin{array}{l}\text { Las infracciones leves se sancionarán } \\
\text { con una multa de cinco a cien jornales } \\
\text { mínimos. } \\
\text { Las infracciones graves se sancionarán } \\
\text { con una multa de ciento uno a } \\
\text { quinientos jornales mínimos. } \\
\text { Las infracciones muy graves, de } \\
\text { quinientos uno a mil quinientos jornales } \\
\text { mínimos. }\end{array}$ \\
\hline
\end{tabular}


Perú
Atentados contra animales de granja, silvestres, vertebrados, acuáticos y de compañía.

Utilización de animales en actos de experimentación, investigación docencia.
Multa no menor de una ni mayor de cincuenta unidades impositivas tributarias.

Clausura parcial o total, temporal o definitiva, del centro o institución donde se lleva a cabo la actividad generadora de la infracción.

Decomiso de los objetos, instrumentos o artefactos utilizados en la comisión de la infracción.

Suspensión o cancelación del permiso, licencia de funcionamiento, concesión o cualquier otra autorización, según el caso.

$\begin{array}{ll}\text { Puerto Rico } & \text { Eelitos: } \\ \text { Graves de segundo grado. } & \text { conlleva una imposición de reclusión de } \\ \text { Graves de tercer grado. } & \text { entre ocho años y un día, y quince años } \\ \text { Graves de cuarto grado. } & \text { o una multa obligatoria desde diez mil } \\ & \text { dólares hasta quince mil dólares. } \\ & \text { En los delitos graves de tercer grado } \\ & \text { conlleva una imposición de reclusión } \\ \text { entre tres años y un día, y ocho años o } & \text { una multa obligatoria desde tres mil } \\ \text { hasta diez mil dólares. } & \text { En los delitos graves de cuarto grado } \\ \text { conlleva una imposición de reclusión de } \\ \text { entre seis meses y un día, y tres años o } \\ \text { una multa obligatoria desde mil hasta } \\ \text { cinco mil dólares. }\end{array}$

República

Dominicana
Ventas de animales en lugares no autorizados

Ventas en lugares públicos.

Negligencia

Maltrato

Crueldad

Reincidencia
Cierre del lugar, multa de entre tres y seis salarios mínimos y entre uno y tres meses de servicios sociales en lugares destinados a la protección y cuidado de animales.

Multa de entre tres y seis salarios mínimos y entre uno y tres meses de servicios sociales en lugares destinados a la protección y cuidado de animales. Prisión de entre tres meses hasta un año y multa de cinco hasta cincuenta salarios mínimos.

Se castigará con el doble de la pena impuesta. 


\begin{tabular}{|c|c|c|}
\hline Uruguay & $\begin{array}{l}\text { Maltrato o lesión a los animales. } \\
\text { Dar muerte a un animal. } \\
\text { Suministrar drogas o medicamentos. } \\
\text { Realizar con animales vivos prácticas de } \\
\text { tiro al blanco. } \\
\text { Manipulación genética. } \\
\text { Promover peleas entre animales. } \\
\text { Alimentos alterados que puedan } \\
\text { provocar la muerte del animal. } \\
\text { Corridas de toros. } \\
\text { Tenencia de animales por personas } \\
\text { incapacitadas. }\end{array}$ & $\begin{array}{l}\text { Apercibimiento. } \\
\text { Multa de una a quinientas unidades } \\
\text { reajustables. } \\
\text { Confiscación de los animales. } \\
\text { Cancelación o suspensión de } \\
\text { autorizaciones, } \\
\text { habilitaciones. } \\
\text { Prohibición temporal o definitiva de } \\
\text { tenencia de animales. }\end{array}$ \\
\hline Venezuela & $\begin{array}{l}\text { Las infracciones se clasifican en: } \\
\text { Leves. } \\
\text { Graves. } \\
\text { Muy graves. }\end{array}$ & $\begin{array}{l}\text { En las infracciones leves se aplicarán } \\
\text { multas que oscilan entre veinte } \\
\text { unidades tributarias a cien unidades } \\
\text { tributarias. }\end{array}$ \\
\hline
\end{tabular}

\section{Discusión}

Luego de analizar país por país de América Latina, partiendo de que la violencia contra los animales se ha ejercido de forma arbitraria, irrespetando la vida, salud y dignidad de estos seres sintientes, se puede evidenciar que, cuentan con normativas protectoras a favor de los animales domésticos, se pudo identificar que la tipificación varia en el ámbito penal como delitos y contravenciones, en el administrativo se establecen como infracciones leves, graves y muy graves, sus sanciones van desde una amonestación, multa hasta una pena privativa de libertad.

La doctrina desde el punto de vista natural exceptúa a los animales como sujetos de Derecho, considerando que el maltrato a estos seres no es un delito contra el medio ambiente, sin embargo, para prevenir y erradicar la violencia contra los animales domésticos, no solamente se necesita de leyes, la problemática radica en la cultura y educación de cada país de considerar a los animales como seres sintientes, no como cosas remplazables. Por otro lado, las reformas como en Ecuador se evidencian mayores castigos a las personas que comentan cualquier acto en contra de los derechos de los animales. 


\section{Conclusión}

En América Latina el maltrato animal es uno de los mayores problemas que enfrenta la sociedad, diversos países de la Región de una u otra manera intentan prevenir, erradicar y sobre todo sancionar las conductas que vulneran los derechos de los animales domésticos, para ejemplificar, en los cuerpos normativos investigados establecen distintas infracciones administrativas como penales, en las primeras se constituyen faltas leves, graves y muy graves, en las segundas se tipifican en delitos públicos como privados y en contravenciones.

Al constituir el maltrato animal un elemento que predispone a la violencia social, el Estado y la sociedad deben trabajar de forma conjunta para erradicar el maltrato animal porque al ser ejercido de forma intencional por personas mentalmente inestables constituye una amenaza tanto para los no humanos, así como humanos, y no debemos ser indiferentes ante la vulneración de derechos de seres indefensos que están bajo nuestra tutela y cuidado.

Se debe proteger a los animales como sujetos de derechos respetando su condición de vulnerabilidad, fomentando medidas que garanticen su bienestar a través de la prevención y educación de la sociedad para evitar el abuso de estos seres vivos que forman parte de nuestras familias y además merecen un trato digno.

\section{Referencias}

Acero Aguilar, M. (2019). Esa relación tan especial con los perros y con los gatos: la familia multiespecie y sus metáforas. Tabula Rasa, (32), 157-179. https://www.redalyc.org/articulo.oa?id=396/39661317008 .

Código Orgánico Integral Penal. Suplemento del Registro Oficial N 180, de fecha 10 de febrero 2014.

Constitución de la República del Ecuador. Registro Oficial 449 de fecha 20 de octubre del 2008.

Demanda de Inconstitucionalidad, Sentencia C-045/19 (Corte Constitucional Colombiana 2019). https://www.corteconstitucional.gov.co/relatoria/2019/C-045-19.htm\#_ftn25

Estrada-Cely, G. E. y Pinto-Díaz, D. F. (2018). Estudio del marco normativo colombiano para equinos como vehículos de tracción a sangre. Ciencia y Agricultura, 15(1), 69-80. https://www.redalyc.org/articulo.oa?id=5600/560063465008

García Solé, M. (2015). El delito de maltrato a los animales. El maltrato legislativo a su protección. Revista de Bioética y Derecho, (18), 36-43. https://doi.org/10.1344/rbd2010.18.7991

Jaurrieta Ortega, I. (2019). El bien jurídico protegido en el delito de maltrato animal. Revista De Derecho UNED, (24), 181-202. https://doi.org/10.5944/rduned.24.2019.25432

Ley N 304087 de protección y bienestar animal. Fecha de presentación 21 de agosto de 2010. Ley Nº 62- Código Penal. Fecha de promulgación 1987.

Ley N 4840 Protección y bienestar animal. Fecha De Promulgación: 28 de enero 2013. 
Ley 70 para la protección de animales domésticos. Asamblea Nacional de Panamá 2012.

Ley № 747 - Ley para la protección y el bienestar de los animales domésticos y animales silvestres domesticados. Publicada en La Gaceta N 96 de fecha 26 de mayo del 2011.

Ley № 700 - Ley para la defensa de los animales contra actos de crueldad y maltrato. Promulgada con fecha 1 de junio de 2015.

Ley $\mathrm{N}^{\circ}$ 14.346. Malos tratos y actos de crueldad a los animales. Boletín Nacional del 05-Nov-1954. Sancionada con fecha 27-09-1954.

Ley N ${ }^{\circ} 1774$ de modificación al Código Civil, Código Penal, Código de Procedimiento Penal, Ley 84 de 1989. Promulgada con fecha 6 de enero 2016.

Ley N1․ 18.471 - Ley de protección, bienestar y tenencia de animales. Publicada D.O. 21 abr/009 - № 27714.

Ley de Protección a los Animales del Distrito Federal. Publicada en gaceta oficial del Distrito Federal de fecha 26 de febrero de 2002, última reforma de fecha 2 de noviembre de 2012

Ley de Protección y Bienestar Animal. Decreto № 115-2015. Promulgación 5 de abril de 2016.

Ley de Protección y Bienestar Animal, Decreto $N^{\circ} 5$ - 2017. Promulgación de fecha 14 de septiembre de 2017.

Ley de Protección y Promoción del Bienestar de Animales de Compañía, Decreto $\mathrm{N}^{\circ} 330$. Promulgación de fecha 07 de abril 2016.

Ley de Protección Animal y Tenencia Responsable Núm. 248-12. Gaceta Oficial Nº 10692 de fecha 15 de agosto de 2012.

Ley de Tenencia Responsable de Mascotas y Animales de Compañía. Promulgación: 19-JUL-2017.

Ley para la protección de la fauna doméstica libre y en cautiverio. Gaceta Oficial Nº 39.338 de fecha 4 de enero de 2010.

Mañalich Raffo, J. P. (2018). Animalidad y subjetividad. Los animales (no humanos) como sujetos-dederecho. Revista de Derecho, 31(2), 321-337. http://dx.doi.org/10.4067/S071809502018000200321

Marín Guzmán, R. (2001). El jainismo: doctrina heterodoxa de la India. Estudio sobre su contribución al desarrollo religioso y cultural de la India (Parte a). Revista de Humanidades: Tecnológico de Monterrey, (11), 137-165. https://dialnet.unirioja.es/servlet/articulo?codigo=2061153

Mazas Gil, B., y Fernández Manzanal, R. (2016). El concepto de bienestar animal en el currículo de Secundaria y en los libros de texto de ciencias. Revista Eureka Sobre Enseñanza y Divulgación de las Ciencias, 13(2), 301-314. https://revistas.uca.es/index.php/eureka/article/view/2969

Molano Bustacara, A., y Murcia Riaño, D. (2018). Animales y naturaleza como nuevos sujetos de derecho: un estudio de las decisiones judiciales más relevantes en Colombia. Revista Colombiana de Bioética, 13(1), 82-103. https://www.redalyc.org/articulo.oa?id=1892/189257376004. 
Mujica Johnson, F. N. (2019). Análisis crítico de la formación actitudinal en la asignatura de Educación Física y Salud en Chile REXE. Revista de Estudios y Experiencias en Educación, 18(38). http://www.redalyc.org/articulo.oa?id=243161557009

Virgen Luján, M. A. (2016). Consideraciones bioéticas sobre el bienestar de bovinos y equinos durante las prácticas quirúrgicas en campo por parte de los estudiantes de Medicina Veterinaria y Zootecnia de la Universidad de la Amazonía. Revista Colombiana de Bioética, 11 (2), 139-164. https://www.redalyc.org/articulo.oa?id=1892/189250583007

Parra Ramírez, E. y Pinzón Zarate, N. J. (2015). Entre la Representación y la Movilización: Escenarios de Participación en Colombia (1991 - 2014). Reflexión Política, 17(34), 60-73. https://www.redalyc.org/articulo.oa?id=110/11043112006

Pérez Vargas, J. J. (2019). El Contractualismo como fundamento de implicación en cuestiones morales sobre la naturaleza y el ambiente. Revista Colombiana de Bioética, 14(1), 69-82. https://www.redalyc.org/articulo.oa?id=1892/189260608005

\section{Contribución de los autores}

SAOP: Conceptualización, investigación, metodología, redacción: revisión y edición.

MDMC: Conceptualización, investigación, metodología, redacción: borrador original.

LGBP: Conceptualización, investigación, metodología, redacción: borrador original.

VEFG: Conceptualización, investigación, metodología, redacción: borrador original.

Fuentes de financiamiento.

La investigación fue autofinanciada.

Conflictos de interés

Los autores declaran no tener conflicto de interés.

Correspondencia

sebastian.ortega@ucacue.edu.ec 